\title{
ESCOLAS PÚBLICAS LOCALIZADAS NO CAMPO NO ESTADO DO PARANÁ: DIRETRIZES CURRICULARES E PRÁTICAS ESCOLARES
}

\section{PUBLIC SCHOOLS LOCATED IN THE FIELD IN THE STATE OF PARANA: CURRICULUM GUIDELINES AND SCHOOL PRACTICES}

\author{
Maria Antônia de Souza* \\ Maria Iolanda Fontana* \\ Patrícia Correia de Paula Marcoccia ${ }^{* *+}$
}

\begin{abstract}
Resumo: Este texto traz uma reflexão sobre as escolas públicas localizadas no campo no estado do Paraná e apresenta resultados parciais de uma pesquisa que está sendo desenvolvida pelo Programa Observatório da Educação (CAPES/INEP). A pesquisa, de perspectiva colaborativa, tem sido desenvolvida mediante a utilização da observação e de seminários com os professores das escolas públicas, com registros em diário de campo. Criou-se, por meio do Observatório, um processo de formação continuada denominado de Cursos de Extensão Itinerantes. Nesse processo formativo discute-se a educação do campo a partir de dois eixos teóricos: prática escolar e experiência coletiva; política educacional e diretriz curricular. Os municípios em que estão localizadas essas escolas possuem características rurais. Apesar disso, verifica-se que as políticas educacionais e as práticas escolares priorizam conteúdos distantes da prática social dos sujeitos que estão na escola, materiais didáticos que valorizam as relações urbanas e colocam os povos do campo em posições inferiores. Constata-se que a maioria das Secretarias Municipais de Educação não teve acesso ao debate e nem à produção do conhecimento da educação do campo; da mesma forma, os professores indicam que pela primeira vez têm podido estudar textos que os inquietam a respeito do campo, trabalho e diversidade de povos.
\end{abstract}

Palavras-chave: Escolas públicas. Educação do campo. Prática escolar.

\begin{abstract}
This text brings a reflection about the public schools located in the field in the state of Parana and presents parcial results of a research that is being developed by Education Observatory Program (CAPES/INEP). The research, collaborative perspective, has been developed through the use of observation, seminars with the teachers from public schools, with records in a rural diary. It was created, through the centre, a continuing education process called "Extension Courses itinerary". In this training process discusses the rural education from two theorical themes: school practice and collective experience; education policy and curriculum guideline. Municipalities in which these schools are located have caracteristics completely rural. Nevertheless, there are policies educational and the schools practices prioritize content of the distants social practice from subjects that are in the school, teaching
\end{abstract}

\footnotetext{
* Doutora. Universidade Tuiuti do Paraná; Universidade Estadual de Ponta Grossa. Email: <maria.antonia@pq.cnpq.br>

* Doctor. Tuiuti University of Paraná; Ponta Grossa State University. E-mail: <maria.antonia@pq.cnpq.br>

${ }^{* *}$ Mestre. Universidade Tuiuti do Paraná. Email: <maria.fontana1@utp.br>

${ }^{* *}$ Master. Tuiuti University of Paraná. E-mail: <maria.fontana1@utp.br>

*** Mestre. Professora da Rede Municipal de Curitiba; Universidade Tuiuti do Paraná. Email: <pa_tyleo@hotmail.com>

****Master. Curitiba Mainstream Municipal Teacher; Tuiuti University of Paraná. E-mail: <pa_tyleo@hotmail.com>
} 
materials that value the relantionships urban and put the rural people in lower positions. It appears that the most of the Municipal Education had no access to the debate and not the production of knowledge in the rural education, the same way, the teachers indicate that the first time have been able to study texts that disquiet about the field, work and diversity of people.

Keywords: Public schools. Rural education. School practice.

\section{Introdução}

O presente artigo traz resultados de pesquisa voltada à compreensão das escolas públicas do campo no estado do Paraná, com ênfase à região metropolitana de Curitiba que possui 252 escolas localizadas no campo, em seus 26 municípios. A pesquisa vincula-se ao Programa Observatório da Educação ${ }^{1}$. É desenvolvida em perspectiva colaborativa com os professores de seis escolas públicas localizadas em cinco municípios da região metropolitana. Neste artigo são apresentadas duas frentes de discussões a partir dos resultados registrados após um ano e meio de investigação.

A primeira frente reporta-se aos registros das características das escolas públicas do campo no estado do Paraná. Essa caracterização foi realizada mediante análise de documentos fornecidos pela Secretaria de Estado da Educação e observação seguida de registro em diário de campo acerca das escolas da região metropolitana

\footnotetext{
${ }^{1}$ O Observatório da Educação materializa-se na parceria entre a CAPES, o INEP e a SECADI, instituído pelo Decreto $n^{0} 5.803$, de 8 de junho de 2006. O programa visa, principalmente, proporcionar a articulação entre pós-graduação, licenciaturas e escolas de Educação Básica e estimular a produção acadêmica e a formação de pós-graduados, em nível de mestrado e doutorado. A Universidade Tuiuti do Paraná integra o Observatório da Educação - Núcleo em Rede UFSC - UFPEL - UTP - por meio do projeto aprovado pelo Edital 038/2010, intitulado Realidade das escolas públicas do campo na região Sul do Brasil: diagnóstico e intervenção pedagógica com ênfase na alfabetização, letramento e formação de professores.
}

A segunda traz análises preliminares de uma experiência formativa, por nós intitulada de Cursos de Extensão Itinerantes, desenvolvida diretamente em escolas públicas municipais localizadas no campo.

A metodologia adotada na experiência formativa integra a concepção de investigação-ação, cuja essência é colaborativa. Ela requer o trabalho coletivo com os sujeitos professores e diretores; o registro dos estudos e da própria prática; a reflexão do conjunto dos participantes para verificação das ações necessárias para a mudança da realidade. Conforme escrevem Grabauska e De Bastos (2001, p.19), “a constituição de comunidades de professores, como investigadores críticos de suas práticas, contribui para a construção de uma ciência educacional crítica, que pode se estabelecer como marco de enfrentamento às concepções técnicas da educação”.

O processo de investigação-ação teve início com um diagnóstico pedagógico feito com os professores, cujo intuito era o de encontrar condições para instituir propostas de formação continuada, na própria escola, mediadas pela atividade da pesquisa sobre a prática escolar na área da alfabetização e letramento.

Nesse tipo de trabalho coletivo é fundamental a participação dos envolvidos nos momentos de planejamento, execução e avaliação para o replanejamento, sendo que as decisões são tomadas por meio de negociações 
com o coletivo dos profissionais. A problematização da prática social e dos problemas emergentes da prática escolar deve ser lida na sua trama de relações e determinações históricas e políticas, demandando o estudo das questões na sua relação teoria e prática.

O processo de formação continuada demanda reuniões nas escolas do campo para fins de reflexão junto com os professores sobre as práticas escolares em relação à alfabetização e letramento, sobre o projeto político-pedagógico e a organização do trabalho pedagógico-administrativo da escola. Em síntese, a metodologia utilizada na pesquisa agrupa as técnicas de observação e registro em diário de campo. O diálogo com os professores das escolas públicas tem sido o ponto-chave para a definição do trabalho com as práticas escolares e a revisão de projetos pedagógicos e planos municipais de educação.

Destacam-se dois eixos teóricos neste artigo. O primeiro diz respeito ao entendimento da educação do campo. É importante esclarecer que a concepção e experiência da educação do campo têm origem na prática coletiva de movimentos sociais como o Movimento dos Trabalhadores Rurais Sem Terra (MST), vinculadas à cultura, identidade e trabalho dos povos do campo. Como escreve Arroyo (2012), historicamente, são povos que vivenciaram diversos processos de segregação. É fundamental lembrar que a educação do campo está atrelada a um projeto político de campo e de país que se contrapõe ao caráter excludente imposto pelo modelo do agronegócio. O segundo eixo teórico refere-se ao conceito de prática escolar, a qual tem sido concebida como atividade com intencionalidade educativa formal. Essa prática está sob a influência de determinantes externos (diretrizes curriculares e processos avaliativos da Educação Básica) e internos (projeto político-pedagógico, planos de ensino, planos de aula, projetos escolares locais), além de todo o conjunto de elementos articuladores que a integra, tal como intencionalidade política, planejamento, relação professor e alunos, processo avaliativo, definição dos conteúdos e estratégias de ensino.

Embora a experiência da educação do campo não esteja reduzida à educação escolar, considera-se fundamental trazer para conhecimento dos professores a produção coletiva, os debates e documentos nacionais e estaduais construídos nos últimos catorze anos no país. Mediante o registro por meio da participação em seminários nacionais, estaduais e regionais é possível verificar que os professores das escolas públicas do campo, em especial os que se vinculam à rede municipal, têm pouco conhecimento sobre a educação do campo e sua trajetória.

Enfim, pretende-se com o artigo trazer os primeiros resultados da modalidade de formação continuada que está sendo denominada de Curso de Extensão Iitinerante. No estado do Paraná, Martins (2008) tem importante obra sobre a formação continuada de professores diretamente na escola do campo e sobre o trabalho coletivo.

Para chegar à caracterização da experiência coletiva - Cursos de Extensão Itinerantes - foi necessário apontar aspectos das escolas do campo no estado do Paraná e destacar a contribuição das diretrizes curriculares. Em função dessa sistemática, este artigo está estruturado em três partes, a saber: 1) caracterização das escolas públicas do campo; 2) reflexões sobre as políticas educacionais com ênfase na construção das Diretrizes Curriculares dos municípios; e 3) apresentação do Curso de Extensão Itinerante que está sendo realizado em municípios da região metropolitana de Curitiba.

É importante destacar que as reflexões empreendidas neste artigo tomam como referência a prática social, suas contradições e 
a intenção de revelar os passos de uma experiência coletiva de educação "virada para o futuro”, nos termos de Suchodolski (2002). Como escreve o autor:

Se queremos educar os jovens de modo a tornarem-se verdadeiros e autênticos artífices de um mundo melhor é necessário ensiná-los a trabalhar para o futuro, a compreender que o futuro é condicionado pelo esforço do nosso trabalho presente, pela observação lúcida dos erros e lacunas do presente, por um programa mais lógico da nossa atividade presente. (p. 102).

Portanto, do ponto de vista do conhecimento educacional, adota-se neste texto a dimensão da totalidade, ao trazer as marcas das escolas públicas no estado; a dimensão da quantidade articulada à qualidade, quando se discute, por exemplo, o fechamento das escolas do campo e os impactos daí advindos, ou quando se analisa a intensidade dos eventos de formação de professores da rede estadual, em oposição à frágil reflexão da educação do campo na rede municipal. Dessa forma, ao analisar a realidade e a prática social em perspectiva ampla, chega-se à proposição de práticas escolares organizadas coletivamente e com a intencionalidade política de empreender duas mudanças no contexto da educação do campo, a saber: 1) valorização das escolas públicas e dos profissionais que trabalham no campo e nas escolas; 2) desencadeamento de processos de reflexão sobre a ruralidade do estado e o necessário redirecionamento do olhar político educacional ao campo e às instituições escolares.

\section{Escolas públicas do campo no Estado do Paraná}

No Paraná existem 399 municípios, os quais na maioria das vezes são compreendidos pelos governantes apenas em seu sentido político e econômico, sem considerar as relações sociais, as identidades dos sujeitos que vivem nesses territórios e o movimento histórico que expressa a luta dos trabalhadores pela sobrevivência.

O estudo de Verde (2004) demonstra o quanto o estado é marcado por características rurais, e deixa claro que o conceito de rural não é dado pelo critério da divisão político-administrativa em perímetro urbano e rural. A definição de rural se dá na inter-relação entre as dimensões espaciais, ambientais, demográficas e culturais, e não apenas na economia e na política. Além disso, a ideia de rural também se amplia e passa a envolver pequenas e médias cidades, pois o jeito de ser rural está presente no campo e na cidade, bem como o vínculo com o trabalho agrícola e agropecuário que é marcante nos diversos municípios do estado.

Nota-se que existem ruralidades no território brasileiro, “embora as relações de trabalho e de classe social [e os processos de exclusão] sejam as mesmas no rural e no urbano" (SOUZA, 2010, p. 55). Com as ruralidades é necessário reconhecer a existência da diversidade no campo brasileiro. Afinal, os espaços rurais não são homogêneos, abrigando diferentes comunidades rurais no mesmo espaço. Essas comunidades podem estar interligadas com os espaços urbanos ou isoladas em outras áreas. Reconhecer essa realidade significa rever o lugar do campo brasileiro enquanto construção histórica, espaço geográfico e social que possui vida, “identidade cultural própria e práticas compartilhadas, socializadas por aqueles que ali vivem” (INEP, 2007, p. 8). Entretanto, todas essas diferenças têm um ponto em comum, estão sustentadas nas desigualdades sociais construídas historicamente no campo brasileiro. 
Essa realidade impõe alguns desafios à educação pública do campo no Paraná (e em todo país), tendo em vista que a educação escolar dos povos do campo ocorre por meio das escolas públicas do estado, as quais necessitam, portanto, (re)pensar seus planos educacionais e conteúdos curriculares, de forma a reconhecer as particularidades de cada comunidade rural e garantir suas identidades nos espaços escolares, mantendo a garantia e o padrão de um ensino de qualidade, conforme posto nas políticas educacionais mais amplas.

Além disso, pensar um projeto de educação do campo pressupõe "estabelecer conexões nas formas de produzir, de se organizar, de lutar e de educar/formar/ensinar a sua base, como forma de se produzir transformações substanciais na própria existência humana desses sujeitos" (VENDRAMINI; MACHADO, 2011, p.87).

No entanto, essas discussões e princípios pouco têm se aproximado da realidade acerca da escolarização dos povos do campo. Um exemplo disso é a realidade das escolas municipais e estaduais que estão localizadas no campo, especialmente na região metropolitana de Curitiba, e que carecem de políticas públicas democráticas.

O estado do Paraná, em 2012, tem em torno de 1.700 escolas no campo. São cerca de 1.100 escolas municipais e 634 escolas estaduais. Desde o ano de 2003, a Secretaria Estadual de Educação tem dado atenção à realidade das escolas públicas do campo. Essa atenção volta-se para a produção de materiais pedagógicos, realização de simpósios e seminários da educação do campo, cursos de formação continuada, elaboração de diretrizes curriculares, diagnósticos das escolas do campo. Todavia, a rede municipal é a que necessita de maior atenção por parte do poder público, pois a maioria dos professores desconhece as experiências e debates da educação do campo. Os professores vivenciam a rotina da viagem até a escola, de imersão no cotidiano escolar, mas se veem diante de esparsas iniciativas governamentais de formação e de valorização da escola pública do campo.

Dados da Secretaria de Estado da Educação registram que 20\% das escolas públicas do estado do Paraná encontram-se no campo. Registra-se que na década de 1990 foram fechados 3.500 estabelecimentos municipais de ensino no estado. Das escolas estaduais existentes no campo, aproximadamente $80 \%$ funcionam em dualidade administrativa. A rede estadual possuía, em 2008, 8.635 professores, sendo 49,60\% do Quadro Próprio do Magistério (QPM) e 50,40\% oriundos do Processo Seletivo Simplificado (PSS). Dos 331.190 alunos residentes no campo, 72,57\% estudam em escolas localizadas na área urbana e 27,43\% estudam em escolas públicas do campo. Em torno de 78\% dos alunos que estudam nas escolas estaduais têm que se locomover para o perímetro urbano para estudar; outros $22 \%$ se locomovem para as escolas localizadas no próprio campo. (PARANÁ, 2010, p.28 - 35).

Esses números revelam que as escolas existentes no campo são insuficientes para atender a demanda das comunidades rurais, particularmente no que se refere ao ensino médio. Esse fato faz ampliar a demanda pelos serviços de transporte escolar, responsável pelo deslocamento dos alunos que moram no campo.

Para ilustrar essa problemática, destaca-se a situação do município de Tijucas do Sul, na região metropolitana. Nesse município, o transporte escolar dispõe de 21 veículos para atender 2.479 alunos: 17 que residem na parte central do município, 877 da Educação Infantil e do Ensino Fundamental que residem na área rural e 1.585 que moram 
no campo e frequentam escolas estaduais. Esses dados revelam como o modelo de educação está comprometido com o processo de nucleação, que transfere os alunos para uma escola-núcleo, localizada em pontos centrais das comunidades, para onde professores e alunos se deslocam fazendo uso do transporte escolar. Além disso, os trajetos são muito longos e, em alguns casos, não atendem a todas as comunidades rurais, além dos casos de alunos que precisam sair muito cedo de casa.

Ao lado dessa realidade em números, há o registro das ações desencadeadas no âmbito educacional no estado do Paraná. Documento produzido pelo Comitê Estadual da Educação do Campo no Paraná destaca que nos dez anos que se sucederam à criação da Articulação Paranaense da Educação do Campo ocorreram as seguintes conquistas: Consolidação da Articulação Paranaense da Educação do Campo e articulações regionais; reconhecimento da diversidade de sujeitos que vivem e trabalham no campo paranaense; estabelecimento de processos de formação continuada de professores mediante parcerias entre Secretaria Estadual de Educação, universidades, movimentos sociais e organizações populares. Também, houve autorização para a criação e o funcionamento de escolas localizadas nas ilhas, nas comunidades quilombolas e indígenas, e de escolas itinerantes nos acampamentos.

Houve uma variada produção bibliográfica e didática destinada aos professores das escolas do campo, bem como o incremento de experiências educacionais tais como: Pedagogia da Terra, Saberes da Terra, Pró-Jovem Campo, Licenciaturas em Educação do Campo, criação da Universidade Federal da Fronteira Sul e da Escola Latino-Americana de Agroecologia, entre outras. Vários projetos político-pedagógicos específicos foram aprovados no estado, tais como o projeto Ciclos de Formação, do Colégio Iraci Salete Strozak, e o projeto das escolas das ilhas. Destaca-se a aprovação das diretrizes estaduais da educação do campo, a criação do comitê estadual e a aprovação da resolução ${ }^{2}$ que dispõe sobre a identidade das escolas do campo, em 2010 (COMITÊ, 2010, p.84-85).

A região metropolitana de Curitiba, tão pouco analisada nos estudos sobre escolas públicas do campo, possui 252 escolas no campo (208 municipais e 44 estaduais) no conjunto dos seus 26 municípios ${ }^{3}$.

O quadro a seguir traz informações sobre o número de escolas estaduais e municipais localizadas no campo, nos 26 municípios da Região Metropolitana.

\footnotetext{
${ }^{2}$ Resolução n 4783/2010-GS/SEED.

${ }^{3}$ Dados da região metropolitana de Curitiba foram levantados pelos membros do Núcleo de Pesquisa em Educação do Campo, Movimentos Sociais e Práticas Pedagógicas (NUPECAMP), da Universidade Tuiuti do Paraná.
} 
Quadro 1 - Número de escolas localizadas no campo na Região Metropolitana

\begin{tabular}{|c|c|c|c|c|c|}
\hline Município & $\begin{array}{l}\text { Escolas } \\
\text { da Rede } \\
\text { Municipal }\end{array}$ & $\begin{array}{l}\text { Escolas } \\
\text { da Rede } \\
\text { Estadual }\end{array}$ & $\begin{array}{l}\text { População } \\
\text { Total }\end{array}$ & $\begin{array}{l}\text { População } \\
\text { Rural }\end{array}$ & $\begin{array}{l}\text { População } \\
\text { Urbana }\end{array}$ \\
\hline ADRIANÓPOLIS & 15 & 2 & 6376 & 4316 & 2060 \\
\hline AGUDOS DO SUL & 8 & 1 & 8270 & 5448 & 2822 \\
\hline ALMIRANTE TAMANDARÉ & 5 & 0 & 103204 & 4312 & 98892 \\
\hline ARAUCÁRIA & 6 & 4 & 119123 & 8918 & 110205 \\
\hline BALSA NOVA & 4 & 3 & 11300 & 4430 & 6870 \\
\hline BOCAIUVA DO SUL & 10 & 0 & 10987 & 5859 & 5128 \\
\hline CAMPINA GRANDE DO SUL & 2 & 1 & 38769 & 6808 & 31961 \\
\hline CAMPO LARGO & 6 & 4 & 112377 & 18206 & 94171 \\
\hline CAMPO MAGRO & 1 & 1 & 24843 & 5296 & 19547 \\
\hline CERRO AZUL & 36 & 1 & 16938 & 12130 & 4808 \\
\hline COLOMBO & 5 & 0 & 212967 & 9764 & 203203 \\
\hline CONTENDA & 3 & 2 & 15891 & 6660 & 9231 \\
\hline CURITIBA & 0 & 0 & 1751907 & - & 1751907 \\
\hline DOUTOR ULYSSES & 23 & 1 & 5727 & 4798 & 929 \\
\hline FAZENDA RIO GRANDE & 2 & 1 & 81675 & 5747 & 75928 \\
\hline ITAPERUÇU & 3 & 1 & 23887 & 3931 & 19956 \\
\hline LAPA & 16 & 6 & 44932 & 17710 & 27222 \\
\hline MANDIRITUBA & 2 & 1 & 22220 & 14806 & 7414 \\
\hline PINHAIS & 0 & 0 & 117008 & - & 117008 \\
\hline PIRAQUARA & 9 & 0 & 93207 & 44469 & 45738 \\
\hline QUATRO BARRAS & 1 & 0 & 19851 & 1910 & 17941 \\
\hline QUITANDINHA & 7 & 6 & 17089 & 12202 & 4887 \\
\hline RIO BRANCO DO SUL & 23 & 2 & 30650 & 8605 & 22045 \\
\hline SÃO JOSÉ DOS PINHAIS & 10 & 5 & 264210 & 27315 & 236895 \\
\hline TIJUCAS DO SUL & 10 & 1 & 14537 & 12252 & 2285 \\
\hline TUNAS DO PARANÁ & 1 & 1 & 6256 & 3464 & 2792 \\
\hline TOTAL & 208 & 44 & & & \\
\hline
\end{tabular}

Fonte: NUPECAMP/Observatório da Educação CAPES/INEP. Organização: Maria Iolanda Fontana e Poliana Pardal, maio de 2012.

No ano de 2000 havia um total de 2.725 escolas municipais localizadas no campo, no estado. Em 2008 esse número era de 1.332 estabelecimentos, representando uma queda de 48\% (PARANÁ, 2010). O fechamento das escolas gera a nucleação de escolas e amplia as necessidades acerca do transporte escolar.

O fechamento dessas escolas não é fruto de uma fatalidade, expressa apenas a forma como a educação escolar dos sujeitos do campo vem sendo tratada pelos municípios, 
estado e União. Apesar de nessa última década haver uma Política Pública Nacional e Estadual da Educação do Campo, formalizada por um aparato jurídico-normativo, a atuação dos governantes revela a fragilidade das medidas, pois as legítimas necessidades dos sujeitos do campo não estão sendo supridas.

No Quadro 1, apresentado anteriormente, é possível identificar que a ruralidade se faz presente, também, na região metropolitana de Curitiba, assim como em todo o território paranaense. Como pode ser visualizado no Quadro, existem municípios cuja população está concentrada na área rural. Existem outros em que há concentração na área urbana, entretanto há neles ampla extensão territorial rural. É possível pensar a concentração da terra, bem como a necessidade de políticas governamentais de incentivo para os trabalhadores do campo brasileiro. No plano educacional, as observações e entrevistas têm indicado o "desconhecimento" das Secretarias Municipais de Educação com as políticas de educação do campo nacional e estadual. Em decorrência, as escolas municipais estão, em sua maioria, influenciadas pela ideologia da educação rural, em que negam os processos históricos do campo brasileiro e trabalham os conteúdos escolares distantes da prática social dos sujeitos que estão na escola, além de utilizar materiais didáticos que valorizam as relações urbanas e colocam o homem do campo em posição inferior.

As discussões sobre as políticas de educação do campo chegam a esses municípios, bem como às suas escolas, por intermédio do programa governamental do Observatório de Educação. A partir do envolvimento dos pesquisadores nos municípios de Araucária, Campo Magro, Quitandinha, Tijucas do Sul e Fazenda Rio Grande, começa a haver interesse dos profissionais das Secretarias Municipais de Educação, diretores e professores em rediscutir o projeto político-pedagógico. Nessa rediscussão, o enfoque estaria nos sujeitos das escolas do campo e nas relações históricas do campo brasileiro, assim como na inserção da educação do campo nos Planos Municipais de Educação, impactando novas possibilidades de desenvolver os conteúdos curriculares em sala de aula.

As experiências com o projeto do Observatório sinalizaram a necessidade de criar outros espaços de estudo e reflexão voltados à formação continuada de professores, diretores e profissionais que trabalham nas Secretarias Municipais de Educação. Nesse sentido, o projeto vem construindo uma prática nas escolas da região metropolitana de Curitiba, prática essa que recebeu a denominação de Cursos de Extensão Itinerantes.

Em síntese, o que se verifica na realidade das escolas públicas do campo no estado do Paraná pode ser resumido em quatro aspectos, a saber: 1) Política de fechamento de escolas, especialmente as municipais. Nos diários de campo os pesquisadores registram a predominância de uma concepção de campo, ainda, como o lugar do atraso. Há necessidade de profissionalização tanto de equipes técnicas quanto dos gestores municipais de educação, de modo que o ensino e as condições de trabalho nas escolas do campo sejam valorizados. 2) Incipiente processo de debate da educação do campo no âmbito municipal e modificação do ritmo de trabalho formativo que vinha sendo feito, na gestão política de 2003 a 2010, com os professores e gestores das escolas do campo. Há necessidade de criação de novas frentes formativas e nos próprios lugares de trabalho dos professores. É assim que surge a proposta de Curso de Extensão Itinerante a ser caracterizado no último tópico deste texto. 3) Efetivação de políticas educacionais no âmbito estadual por meio das ações da coordenação da educação 
do campo, de 2003 a 2010. Constituiu-se na referida conjuntura uma esfera pública em que governos e sociedade civil organizada foram os protagonistas de processos formativos, com a definição de linhas políticas tais como a produção de cadernos temáticos da educação do campo e as diretrizes curriculares estaduais. Governo e sociedade civil traçaram os rumos da educação do campo no Paraná, mediante valorização da experiência coletiva dos movimentos sociais e organizações populares. Fortaleceram-se as parcerias entre a sociedade civil e o governo no período de 2003 a 2010. 4) Predomínio da ideologia de que o urbano é superior ao rural. Essa visão tem sido registrada nas falas de secretários municipais de educação, de diretores e de professores que aprenderam, ao longo da trajetória escolar, a pensar o Brasil como se fosse unicamente urbano. É uma visão que necessita ser problematizada para ser superada.

Em síntese, a realidade da educação do campo no Paraná gerou demandas por parte dos movimentos sociais dentro da instância governamental. Com a criação da coordenação da educação do campo, os diálogos entre sociedade civil e governos foram fecundos para a construção de uma política educacional centrada na experiência coletiva. A política educacional se faz na esfera pública, que, por sua vez, é o espaço de encontro entre o que demanda e propõe a sociedade e o que o governo de fato efetiva. Nessa esfera pública foi construído o documento que constitui as diretrizes curriculares do estado do Paraná e foi suscitado o envolvimento dos municípios no que diz respeito aos encaminhamentos políticos e pedagógicos de interesse dos povos do campo.

\section{Diretrizes Curriculares da educação do campo no Paraná}

A partir de 2003, a coordenação da educação do campo passou a ser um dos protagonistas fundamentais no avanço da educação do campo. Tornou-se um espaço de diálogo entre os movimentos sociais do campo e o governo. Em 2011, numa nova conjuntura política, tal coordenação recebeu a denominação de Coordenação Escolar da Educação do Campo, reduzindo assim a esfera pública de debate, experiências e parcerias de educação do campo.

No período de 2003 a 2010 foram fortalecidas, no estado, as experiências e discussões da educação do campo, buscando instituí-la como uma política pública educacional. Foram organizados diversos seminários, simpósios e eventos de formação continuada para professores e pedagogos, no intuito de aprofundar discussões teóricas e práticas sobre a educação do campo, além de se ter elaborado materiais pedagógicos construídos a partir das demandas surgidas nos eventos e nos grupos de estudos.

É a partir desse contexto que a educação do campo insere suas concepções e propostas nas esferas governamentais. Um exemplo disso foi a elaboração e implementação das Diretrizes Estaduais da Educação do Campo, documento constituído com a ajuda dos profissionais da educação das escolas do campo e representantes de movimentos sociais do campo, com a intenção de "traçar estratégias que visam nortear o trabalho do professor e garantir a apropriação do conhecimento pelos estudantes da rede pública” (PARANÁ, 2006, p. 5).

As Diretrizes orientam os professores a articularem a prática social dos povos do campo com os conhecimentos historicamente construídos pela humanidade, reconhecidos 
e trabalhados nas instituições escolares. Além de trazer subsídios à prática escolar, o documento aborda a concepção de campo, mostrando que este está além do perímetro rural e deve ser compreendido pelas "particularidades dos sujeitos e não apenas [por] sua localização espacial e geográfica” (PARANÁ, 2006, p. 22). Assim, inicia-se o reconhecimento da identidade da escola do campo e, consequentemente, dos diversos sujeitos que vivem no campo.

A partir das reflexões advindas das diretrizes curriculares, os professores demandaram do estado o esclarecimento sobre a identidade das escolas do campo. Em função disso, foi publicada a Resolução n 4783/2010 - GS/ SEED, que institui a educação do campo como política pública no estado do Paraná e define em seu artigo $3^{\circ}$ a identidade das escolas do campo como sendo "[...] aquelas inseridas em comunidades caracterizadas pelo vínculo e trabalho com a terra, independente de sua localização". Essa resolução traz um avanço para a política educacional do estado e para a valorização dos povos do campo, pois possibilita que escolas localizadas na "periferia" dos núcleos urbanos, que recebem alunos do campo, sejam identificadas como escolas do campo. No âmbito curricular, tal inovação exige que os professores, diretores e coordenadores pedagógicos reestruturem os projetos político-pedagógicos adequando-os às diretrizes curriculares da educação do campo

Algumas experiências de revisão dos projetos político-pedagógicos têm sido desencadeadas pelas secretarias municipais, mas todas elas mediante a intervenção de processos formativos oriundos de parcerias, capacitação ou cursos efetivados em conjunto com as universidades. São exemplos de municípios que vêm reestruturando o projeto político-pedagógico, na região metropolitana, Araucária, Campo Magro, Tijucas do Sul, Fazenda Rio Grande e Quitandinha.
Os processos de investigação-ação desencadeados no âmbito do projeto Observatório da Educação têm gerado a necessidade e a disposição dos profissionais para a reestruturação do projeto político-pedagógico. E como tais processos têm ocorrido? Inicialmente são discutidos aspectos da realidade local, tais como a identificação dos sujeitos e do tipo de trabalho existente no campo; posteriormente são definidos com os professores textos centrais para estudo (temas como identidade, cultura, educação do campo e diversidade); desenvolvem-se debates sobre os conteúdos estudados e, por fim, analisa-se o conteúdo do projeto político-pedagógico, identificando-se qual é a concepção de educação e de campo nele presente. Em todos os municípios os próprios professores identificaram que o campo, quando aparece no projeto político-pedagógico, vem atrelado a uma concepção de “atraso”. Essa primeira constatação é que aumenta a disposição dos professores para o estudo e modificação do projeto pedagógico, articulando-o aos aspectos culturais, econômicos e sociais locais.

Aos poucos a equipe se aproxima dos eixos temáticos indicados nas diretrizes da educação do campo do estado do Paraná, a saber: trabalho (divisão social e territorial); cultura e identidade; interdependência campo-cidade, questão agrária e desenvolvimento sustentável; organização política, movimentos sociais e cidadania. (PARANÁ, 2006)

Portanto, no que diz respeito às diretrizes curriculares, quatro aspectos podem ser apontados.

Primeiro: o documento foi elaborado com o intuito de instituir no estado do Paraná um processo de reconhecimento dos povos do campo. Para esse reconhecimento foi necessário organizar e efetivar parcerias para fins de diagnóstico da realidade escolar, 
cursos para incentivo ao estudo do campo brasileiro e da concepção de educação do campo, seminários, simpósios e produção de material didático.

Segundo: o processo de divulgação das diretrizes gerou a necessidade de analisar os livros didáticos, os projetos político-pedagógicos e os processos avaliativos. Afinal, a rotina escolar no campo raramente era diferenciada da rotina nas escolas da cidade. Com as diretrizes e com a Lei de Diretrizes e Bases de 1996, houve possibilidade de problematizar a mudança do calendário escolar e dos horários das aulas, em locais nos quais tanto o trabalho na agricultura como o tempo (muita chuva, por exemplo) dificultavam o acesso das crianças à escola e sua permanência na instituição. Assim, as diretrizes estaduais vieram reforçar a necessidade de se discutir as particularidades dos povos do campo.

Terceiro: com o avanço dos estudos em educação do campo no estado, houve necessidade de produção de material pedagógico que enfatizasse o conceito de diversidade e caracterizasse as categorias de trabalhadores do estado, a exemplo dos assentados, acampados, faxinalenses, comunidades quilombolas, ilhéus, pequenos produtores, bóias-frias entre outros.

Quarto: as diretrizes da educação do campo do estado vão exigir que a prática escolar seja repensada. Em função disso, foram realizadas muitas oficinas pedagógicas nas diversas áreas do conhecimento, com o intuito de motivar o professor da escola do campo a estabelecer relações entre os conteúdos escolares, científicos e os conhecimentos da experiência de vida. Dessa forma, incentiva-se o professor a observar as características do campo brasileiro, a interrogar a própria realidade, as contradições que a marcam. No entanto, constatou-se - em pesquisas realizadas nas seis ${ }^{4}$ escolas integradas ao Observatório - a ausência de formação continuada para os professores, na área específica da educação do campo.

Enfim, é com o intuito de preencher essa ausência e propiciar um repensar da prática escolar pelo próprio professor que se criou o Curso de Extensão Itinerante, analisado a seguir.

\section{Práticas escolares de alfabetização e letramento na escola do campo: o Curso de Extensão Itinerante}

O Curso de Extensão Itinerante foi criado em 2011, pela equipe do Núcleo de Pesquisa em Educação do Campo, Movimentos Sociais e Práticas Pedagógicas, no contexto do projeto Observatório da Educação em desenvolvimento desde janeiro de 2011. Esse curso vem caracterizar uma nova modalidade de trabalho coletivo e de formação continuada. Tem como princípio educacional que é a indissociabilidade entre ação e reflexão que gera a transformação na própria prática. Dessa forma, o curso estrutura-se nos seguintes movimentos: 1) Despertar da equipe para o estudo da prática escolar, do projeto político-pedagógico e função social da escola no que diz respeito à alfabetização e letramento. 2) Organização dos estudos coletivos e registros da prática em diários de campo. 3) Planejamento de atividades na própria escola. Esse planejamento é realizado a partir das necessidades apontadas pelos professores. 4) Identificação dos principais desafios a serem superados no que diz respeito à prática escolar e à concepção de

\footnotetext{
${ }^{4}$ As seis escolas estão localizadas na região metropolitana de Curitiba, nos municípios de Araucária (duas escolas), Campo Magro, Fazenda Rio Grande, Quitandinha e Tijucas do Sul.
} 
mundo, em especial o relacionado ao campo/ rural brasileiro.

O Curso de Extensão é itinerante por ser realizado nas escolas do campo, em cinco municípios da região metropolitana. Muda-se de lugar, de tema e de estratégia de estudo conforme as principais problemáticas apontadas pelo grupo. Por exemplo, o município de Tijucas deseja fazer uma reestruturação coletiva do projeto pedagógico que orienta as escolas do campo. O município de Quitandinha deseja fazer reformulação do projeto político-pedagógico de uma escola localizada no campo. Segundo a coordenadora pedagógica, a concepção de campo presente nesse projeto está em oposição aos princípios e critérios dispostos nas diretrizes nacionais e estaduais da educação do campo. O município de Araucária tem feito revisão do plano municipal de educação, com participação de coordenadores pedagógicos e diretores das escolas do campo. Dessa forma, verifica-se que o Curso de Extensão Itinerante pode fortalecer processos político-pedagógicos que já estão em andamento e dar origem a estudos e problematização da realidade local em municípios que ainda não participam do movimento da educação do campo.

O município de Campo Magro foi o escolhido para a descrição de como tem acontecido o curso de extensão. É importante registrar que para os professores é uma novidade o fato de os cursos acontecerem na própria escola do campo e em conformidade com as necessidades pedagógicas locais.

Em Campo Magro, o curso desenvolve-se na Escola Professora Mercedes Marques dos Santos, que atende 226 alunos distribuídos em cinco turmas no turno da manhã e cinco no turno da tarde. Essa escola teve o IDEB de 4,1, e o município registra o Î́ndice de Desenvolvimento Humano de
0,74\%. Nela trabalham uma diretora, uma pedagoga, nove professoras, sendo que seis delas atuam nos dois turnos escolares. Todas as professoras da escola têm formação em nível superior, sendo que a maioria delas cursou a distância.

Realizou-se na escola a exposição dos objetivos da pesquisa e dos procedimentos que seriam utilizados no processo de investigação, envolvendo o coletivo de profissionais para o diagnóstico, análise e intervenção em problemas detectados. Com o conjunto de professores, definiram-se como procedimentos de pesquisa a observação em sala de aula, diálogos com o grupo de professores, diretora e pedagoga, entrevistas e análise dos diários de aula elaborados pelas professoras.

Inicialmente, constatou-se que não existe horário comum para o planejamento coletivo do trabalho pedagógico. Há previsão de duas horas semanais para cada professora realizar o planejamento e avaliação das atividades realizadas pelos alunos, e quando é possível a pedagoga acompanha esse trabalho. Essa condição já indica dificuldades que a equipe escolar tem para organizar, analisar, pesquisar e planejar o trabalho pedagógico, fato que aponta a necessidade de políticas públicas que melhorem as condições de trabalho, a lotação e valorização da permanência de profissionais nas escolas do campo.

No desenvolvimento da investigação-ação, fez-se necessário reorganizar o tempo escolar, para envolver o coletivo dos profissionais da escola nas atividades de diálogo sobre os problemas da prática pedagógica relacionados aos conteúdos e métodos de alfabetização e letramento.

Tomou-se como referência para a presente pesquisa a questão: Quais intervenções pedagógicas se fazem necessárias nas escolas do campo, especialmente quando se trata de pensar a ampliação das habilidades de 
leitura dos professores quanto aos conhecimentos relacionados às contradições da sociedade brasileira, em particular no campo, e aos conhecimentos específicos necessários a alfabetização e letramento dos estudantes dos anos iniciais do Ensino Fundamental?

A partir dessa indagação foram estruturados os instrumentos de levantamento de dados, cujos resultados e análises apresentam-se em categorias que envolvem a formação profissional dos professores e a prática pedagógica de alfabetização e letramento na escola do campo.

Sobre a formação das professoras, os dados coletados nos questionários e diálogos realizados denotam fragilidades teóricas e práticas que limitam a sua atuação frente à realidade da escola do campo. A maioria das professoras diz ter dificuldades de conhecimentos didático-metodológicos para melhorar a aprendizagem de alunos, principalmente daqueles que apresentam dificuldades para avançar no processo de aquisição da leitura e escrita. Nos questionários e falas fica evidenciada a queixa sobre a falta de acompanhamento das famílias nos estudos dos filhos e de compromisso com a escola. Os dados revelam ainda que as professoras reconhecem a necessidade de estudar e compreender a realidade do campo e dos seus sujeitos para nela melhor intervir. Queixam-se de falta de formação continuada para o enfrentamento dessa realidade.

Destaca-se o que dizem as professoras da referida escola, quando questionadas sobre quais ações consideram necessárias para melhorar o seu trabalho e a aprendizagem dos seus alunos:

"Uma formação específica para nós professores do campo para melhor trabalharmos a realidade do campo $e$ sua importância para a sociedade." (PROFESSORA F, 2011).
"Ter uma formação profissional de acordo com a realidade do campo para que possamos dar mais importância a essa área que muitas vezes acaba ficando de lado. E um maior comprometimento dos pais em relação à aprendizagem dos filhos." (PROFESSORA C, 2011).

"Mais cursos profissionalizantes para o professor aprender não só o teórico, mas sim a prática principalmente com os alunos com bastante dificuldades." (PROFESSORA G, 2011).

As professoras foram questionadas sobre a frequência do trabalho com textos que abordam os temas da realidade do campo. Com exceção de uma professora que respondeu que utiliza esses textos sempre que necessário, principalmente na área de História e Geografia, as demais responderam que tais temas são poucas vezes trabalhados. Elas justificam o pouco tempo para a pesquisa, o desconhecimento do assunto e até a pouca importância dada a esses conteúdos, como exemplificam as falas:

"Não sei o suficiente sobre o assunto para ter segurança para trabalhar com o assunto." (PROFESSORA B, 2011).

"Talvez por não ter consciência de importância desse trabalho com o tema, acreditando que é melhor abordar temas diferentes, mostrar o novo." (PROFESSORA F, 2011)

"Falta de tempo e muitas vezes conhecimento científico sobre o mesmo." (PROFESSORA G, 2011).

A inadequação do projeto pedagógico à realidade do campo foi verificada na análise do documento feita pelas pesquisadoras, logo no início do processo de investigação na escola. As professoras relatam que não sabem como fazer a adequação curricular para melhor atender às especificidades do campo e também alegam que não receberam orientação técnica da mantenedora. 
Com base em tais dados, e a partir da solicitação das professoras, fez-se o planejamento para momentos de leituras coletivas na escola, de documentos oficiais sobre as políticas governamentais para a formação de professores, de teorias e pesquisas desenvolvidas sobre a educação do campo, destacando-se entre os autores: Frigotto (2010), Munarim (2010) e Souza (2008; 2011).

Pretende-se com os estudos desenvolver uma pedagogia do campo que tome como ponto de partida a particularidade e singularidade de homens e mulheres que produzem suas vidas no campo. Nessa pedagogia, "não se postula o localismo e nem o particularismo, mediante os quais se nega o acesso e a construção do conhecimento e de uma universalidade histórica rica, porque é a síntese do diálogo e da construção de todos os espaços onde os seres humanos produzem sua vida”. (FRIGOTTO, 2010, p.36). Entende-se ser este um desafio que demanda pesquisas e debates na escola, para efetivamente construir saberes e práticas pedagógicas que ultrapassem a reprodução de modelos urbanos em realidades singulares do campo.

No que diz respeito às práticas escolares, realizou-se, como dito anteriormente, a observação em sala de aula, a aplicação de questionário e a verificação dos diários organizados pelas professoras, nos quais são registradas as atividades realizadas pelos alunos em sala de aula. Esses diários utilizados em todas as escolas do município de Campo Magro são denominados de "cadernos itinerantes”, pois é por meio deles que a coordenação pedagógica do município faz o acompanhamento do trabalho realizado nas escolas.

As observações realizadas nas salas de aula do $1^{\mathrm{o}}$ ao $5^{\mathrm{o}}$ ano $/ 4^{\mathrm{a}}$ série, no ano de 2011, detiveram-se no primeiro ano de pesquisa aos aspectos da organização do espaço e dos alunos na sala de aula. As atividades pedagógicas de alfabetização e letramento foram analisadas por meio dos cadernos itinerantes e de questionário.

Quanto à organização do espaço e dos alunos em sala, constata-se que há diferenças entre os procedimentos utilizados pelas professoras. Nas turmas de $1^{\circ}$ ano e $2^{\circ}$ ano, estão expostos poucos materiais para motivação da escrita e leitura, os alunos são agrupados em duplas e as professoras circulam na sala para acompanhar a realização das atividades. Não se observou o trabalho em grupos nas turmas de $3^{\circ}, 4^{\circ}$ e $5^{\circ}$ ano $/ 4^{a}$ série, sendo que a sala de aula está organizada em filas de carteiras e quase não há exposição de materiais didáticos. É consenso entre os autores que estudam o processo de alfabetização e letramento a importância de construir com os alunos um ambiente alfabetizador; um ambiente que veicule, por meio de textos, imagens, letras do alfabeto, as práticas sociais de leitura e escrita, inserindo a criança em contextos de letramento.

Para verificação das atividades de alfabetização e letramento desenvolvidas pelas professoras, registradas nos cadernos itinerantes, estabeleceram-se critérios de análise, utilizando-se, como referência, os descritores de aprendizagem de leitura e escrita adotados pelo MEC/INEP na prova Brasil. São denominados descritores a "associação entre conteúdos curriculares e operações mentais desenvolvidas pelos alunos que traduzem certas competências e habilidades”. (BRASIL, 2008, p.18).

A análise tomou como referência as atividades selecionadas pelas professoras, durante o $2^{\circ}$ trimestre do ano de 2011, com o objetivo de verificar quais conteúdos curriculares e estratégias metodológicas elas têm privilegiado no processo de alfabetização eletramento. Identifica-se que a maioria das atividades trabalhadas envolve a apresentação 
de textos, principalmente os poéticos e narrativos, no $1^{\circ}$ e $2^{\circ}$ ano; e informativos no $3^{\circ}$, $4^{\circ}$ e $5^{\circ}$ ano $/ 4^{a}$ série. Os textos abordam temas variados - principalmente relativos às áreas de Ciências e História - acompanhados de atividades de interpretação. Constata-se que apenas uma professora desenvolve o trabalho com unidades temáticas, apresentando diferentes tipologias textuais para um mesmo tema. Verificou-se a ausência de textos sobre a realidade do município; localizou-se apenas um texto informativo sobre a fundação da cidade, trabalhado por todas as professoras, e sobre as atividades de agricultura no município, no $3^{\circ}$ ano.

As atividades de interpretação solicitam aos alunos, quase sempre, habilidades de localização de informação explícita no texto. Com menor frequência, no $5^{\circ}$ ano $/ 4^{a}$ série, as professoras solicitam aos alunos a localização de informação implícita no texto, identificação do tema, da finalidade de textos de diferentes gêneros, de conflito de um enredo, e o estabelecimento de relações causa/consequência entre as partes do texto.

Constata-se que, nos cadernos itinerantes do $1^{\circ}$ ao $5^{\circ}$ ano, não há propostas de produção de textos; apenas frases, ditados de palavras e exercícios para fixação das normas gramaticais. Nos três primeiros anos, não se observou a sistematização de atividades de correspondência grafo/sonora e de consciência fonológica, ou seja, de exercícios de atenção aos sons da fala e da escrita. Quanto à oralidade, aparecem apenas registros de solicitação de opiniões sobre os assuntos estudados.

As atividades de leitura e escrita selecionadas pelas professoras mostram fragilidades na sistematização e seleção dos conteúdos de ensino em cada ano escolar. Também preocupante é a falta de atividades de produção de textos e do contexto de letramento nas atividades de codificação e decodificação do sistema alfabético.

Soares (2003, p. 69-70) esclarece que os professores devem ter como objetivo proporcionar aos alunos condições para se aprimorarem nas habilidades de leitura e escrita. As atividades de leitura devem promover a capacidade de interpretar sequências de ideias e eventos, analogias, comparações, linguagem figurada, relações complexas, conhecimentos prévios e informação textual de forma interpretativa. Quanto às atividades de escrita, que se constituem como a maior fragilidade observada na escola, o professor deve incentivar a produção de diversos tipos de textos, preparando o aluno para expressar ideias e organizar o pensamento de forma gráfica adequada, dirigindo-se a um leitor potencial e mantendo com ele a desejada interlocução.

Autores como Soares (2004), Leite (2010) asseveram que houve a partir da década de 1980 o abandono dos métodos de alfabetização e a restrição velada de atividades de sistematização, pois tais atividades chocavam-se com a ideia da construção individual do conhecimento. Cabem investigações para verificar se a falta de sistematização dos conteúdos da alfabetização na escola se deve a essa premissa, ou decorre da falta de planejamento da ação pedagógica; ou, ainda, de lacunas de conhecimento metodológico de alfabetização e letramento.

Por essa razão, decidiu-se trabalhar com as professoras a investigação da própria prática escolar, no que concerne ao conteúdo e método da alfabetização e letramento. Segundo Soares (2008), o professor somente estará habilitado para uma ação pedagógica competente se o seu processo de formação for marcado pelas pesquisas nas áreas específicas de atuação. A autora reforça que não basta ao professor conhecer o sistema 
ortográfico da língua portuguesa, ou estar informado sobre teorias psicológicas ou psicolinguísticas. Porém, é fundamental que o professor "conheça as pesquisas lingüísticas sobre as relações entre o sistema fonológico e o sistema ortográfico, as pesquisas psicolingüísticas sobre a aquisição do sistema ortográfico pela criança, as pesquisas psicológicas sobre a aprendizagem e o desenvolvimento cognitivo". (SOARES, 2008, p. 101).

Em sua dissertação de mestrado sobre as condições de letramento de professores de municípios do estado do Paraná, Reis (2009) constata a estreita relação entre o nível de letramento dos professores e a qualidade das intervenções pedagógicas que realizam. A autora descobriu que os professores pouco escrevem e isso reflete em sua prática pedagógica, confirmando a argumentação de Kramer e Souza (1996, p. 10): "para o professor tornar seus alunos leitores/escritores vivos precisa ser ele mesmo leitor e escritor".

Busca-se por meio da investigação-ação qualificar os processos de formação continuada na escola, visando à revisão do planejamento da prática pedagógica de alfabetização e letramento e ao desenvolvimento da leitura, escrita e interpretação de textos vinculados à realidade brasileira, em particular ao campo. Pretende-se, dessa forma, desenvolver estratégias de trabalho coletivo nas escolas do campo, mediante ênfase na investigação-ação e no levantamento de dados sobre as condições de letramento dos professores e sobre os conhecimentos específicos sobre alfabetização e letramento dos estudantes, como também sobre os conteúdos socioambientais locais.

\section{Considerações finais}

As pesquisas desenvolvidas no estado do Paraná têm permitido analisar as escolas do campo, a prática escolar e as diretrizes curriculares a partir do conceito de experiência e de política educacional. A experiência no contexto da educação do campo é para ser coletiva, porém o que se verifica na maior parte dos municípios é que os professores estão em meio à rotina escolar de planejamento do ensino, desenvolvimento das aulas, execução de projetos escolares, viagens até a escola, encontros nas secretarias municipais. Essa rotina produz uma experiência bastante centrada no fazer e reduzida no que tange à observação e reflexão da própria prática e do entorno onde se encontra a escola. Fato é que muitos professores ficam admirados quando descobrem que nunca tinham pensando no campo ou nos povos do campo, em particular na região metropolitana. Dessa forma, fica-se diante de uma experiência que nem é vivida como classe - trabalhadora e nem é percebida em sua cultura, valores e sentimentos.

Nesse cenário são produzidas as políticas educacionais, muitas delas centradas na equipe de coordenadores pedagógicos e gestores da educação, fundados na lógica da racionalidade econômica. O que se busca é a construção, no âmbito municipal, também de políticas oriundas da participação dos interessados na formação escolar e humana.

Neste artigo foram apresentadas características das escolas do campo no Paraná e pode-se dizer que a principal delas tem sido o fechamento de escolas. Eis uma decisão que é política - dos gestores municipais em diálogo com as comunidades - e é cultural, pois há uma ideologia que força a mente crer que o ensino na cidade é melhor; que o campo tem que ser superado. Essa ideologia 
é oposta a todos os estudos que mostram que a viabilidade de uma sociedade econômica e socialmente sustentável encontra-se na definição de políticas de geração, emprego e formação escolar no campo. Ao final, foram pontuados elementos vinculados às diretrizes curriculares, sendo que o processo de formação continuada é o que mais chama a atenção e, com ele, a importância da elaboração de práticas diferenciadas de debate pedagógico e político, a exemplo dos cursos de formação itinerantes.

\section{Referências}

ARROYO,M.G.Diversidade.In:CALDART, R.S. et al. (Orgs.). Dicionário da educação do campo. Rio de Janeiro: Escola Politécnica de Saúde Joaquim Venâncio; São Paulo: Expressão Popular, 2012.

BRASIL. Ministério da Educação. PDE: Plano de Desenvolvimento da Educação. Prova Brasil - ensino fundamental: matrizes de referência, tópicos e descritores. Brasília: MEC, SEB; Inep, 2008.

COMITÊ ESTADUAL DA EDUCAÇÃO DO CAMPO. Gestão de políticas públicas educacionais da educação do campo. Curitiba, 2010.

FRIGOTTO, G. Projeto societário contra-hegemônico e educação do campo: desafios de conteúdo, método e forma. In: MUNARIM, A. et al. (Org.). Educação do campo: reflexões e perspectivas. Florianópolis: Insular, 2010.

GRABAUSKA, C. J.; DE BASTOS, F. da P. Investigação-ação educacional: possibilidade crítica e emancipatória na prática educativa. In: MION, R. A.; SAITO, C. H. (Orgs.). Investigação-ação: mudando o trabalho de formar professores. Ponta Grossa: Gráfica Planeta, 2001.
INSTITUTO NACIONAL DE ESTUDOS E PESQUISAS EDUCACIONAIS ANÍSIO TEIXEIRA - INEP. Panorama da Educação do Campo. Brasília, DF: INEP, 2007. Disponível em: <http://www.red-ler.org/panorama-educacao-campo.pdf $>$. Acesso em: 5 agosto 2011.

KRAMER, S.; SOUZA, S. J. (Org.). História de professores: leitura, escrita e pesquisa em educação. São Paulo: Ática, 1996.

LEITE, S. A. S. Alfabetização: em defesa da sistematização do trabalho pedagógico. In: LEITE, S. A. S.; COLELLO, S. M. G (Orgs.). Alfabetização e letramento: pontos e contrapontos. São Paulo: Summus, 2010.

MARTINS, F. J. (Org.). Educação do campo e formação continuada de professores. Porto Alegre: EST Edições; Campo Mourão: FECILCAM, 2008.

MUNARIM, A. Educação do campo: desafios teóricos e práticos. In: MUNARIM, A. et al. (Org.) Educação do campo: reflexões e perspectivas. Florianópolis: Insular, 2010.

PARANÁ. Secretaria de Estado da Educação. Diretrizes curriculares da Educação do campo. Curitiba: SEED, 2006.

Superintendência de Educação. As escolas públicas do campo no Estado do Paraná: uma identidade em construção. Curitiba: SEED, 2010.

REIS, M. R. A condição de letramento dos professores das séries iniciais do ensino fundamental. 108p. Curitiba, 2009. Dissertação (Mestrado em Distúrbios da Comunicação). Universidade Tuiuti do Paraná.

SOARES, M. As pesquisas nas áreas específicas influenciando o curso de formação de professores. In: ANDRÉ, M. E. D. A. O papel da pesquisa na formação e na prática dos professores. 9. ed. Campinas/SP: Papirus, 2008. 
. Letramento e alfabetização: as muitas facetas. Revista Brasileira de Educação, n.25, 2004. Disponível em: < http:// www.scielo.br/pdf/rbedu/n25/n25a01.pdf/>. Acesso em: 5 agosto 2011.

- Letramento e escolarização. In: RIBEIRO, V. M. (Org.) Letramento no Brasil. São Paulo: Global Ação Educativa. Instituto Paulo Montenegro, 2003.

SOUZA, M. A. Educação do campo: políticas, práticas pedagógicas e produção científica. Educação e Sociedade, n. 105, Campinas, dezembro de 2008.

Práticas educativas do/no campo.

Ponta Grossa: Editora UEPG, 2011.

Educação e movimentos sociais

do campo: a produção do conhecimento no período de 1987 a 2007. Curitiba: UFPR, 2010.

SUCHODOLSKI, B. A pedagogia e as grandes correntes filosóficas: a pedagogia da essência e a pedagogia da existência. São Paulo: Centauro, 2002.

VENDRAMINI, C. R.; MACHADO, I. F. A relação trabalho e educação nas experiências escolares do MST. In: VENDRAMINI, C. R.; MACHADO, I. F. (Orgs.). Escola e movimento social: experiências em curso no campo brasileiro. São Paulo: Expressão Popular, 2011.

VERDE, V. V. Territórios, ruralidade e desenvolvimento. Curitiba: Instituto Paranaense de Desenvolvimento Econômico e Social (Ipardes), 2004.

Recebido em: 08/07/2012

Aceito em: 21/07/2012 